\title{
Vibration and Position Monitoring in Civil Structures using WI-FI Systems
}

\author{
Wander P. Jesus \\ Evandro J. G. Lima \\ Joyce R. Silva \\ Rafael G. Alvares \\ Zelia M. A. Peixoto
}

\section{CITE THIS ARTICLE}

Jesus, Wander P., Lima, Evando J. G., Silva, Joyce R., Alvares, Rafael G. and Peixoto, Zelia M. A.; 2019. Vibration and Position Monitoring in Civil Structures using WI-FI Systems. SET INTERNATIONAL JOURNAL OF BROADCAST ENGINEERING. ISSN Print: 2446-9246 ISSN Online: 2446-9432. doi: 10.18580/setijbe.2019.12. Web Link: http://dx.doi.org/10.18580/setijbe.2019.12 


\title{
Vibration and Position Monitoring in Civil Structures using WI-FI Systems
}

\author{
Wander P. Jesus, Evandro J. G. Lima, Joyce R. Silva, Rafael G. Alvares \\ and Zelia M. A. Peixoto, Member, IEEE
}

\begin{abstract}
This study presents the design, development and experimental implementation of a system for monitoring and signaling of vibration and position in civil structures, aiming to provide tools to perform predictive maintenance. Basically, the proposed system consists of an Espressif 32-bit microcontroller from the ESP32 chip series and a gyroscope and accelerometer module for vibration and position measurements. The system communicates via Wi-Fi with Android-based smartphones, using the Blynk app, which is specially designed for IoT applications. It also has its own electric power generation unit from a solar panel, what makes it autonomous and flexible. Test results confirm a good prototype performance, adaptability for different civil structures and indicates promising possibilities for future applications.
\end{abstract}

Index Terms - Accelerometer, Gyroscope, IoT, Predictive Maintenance, SHM, Structural Health Monitoring, Vibration.

\section{INTRODUCTION}

$\mathrm{C}_{\mathrm{s} u}^{\mathrm{n}}$ IVIL structures are fundamental in the current world's scenario due to its importance in urban traffic or cities connections through bridges and viaducts, housing and business, large reservoirs used for tailings and hydrographic dams in industries and energy generation, among others. A commonality in the mentioned structures is the need of safety for users and actions that can prevent upheavals or serious accidents, which makes it mandatory that any changes in these structures must be monitored [1].

In this context, this work consists of design, development, experimental implementation and testing of a monitoring system that makes measurements related to the occurrence of vibrations and displacements in civil structures based on a pre-established standard, considered as a reference for the project. Upon changes in this pattern, the user will receive a signal and thus will be able to intervene in advance to meet safety standards, reducing costs and preventing structural collapses.

W. A. Jesus (wander.pjesus@gmail.com), E. J. G. Lima (evandrojgr@gmail.com), J. R. Silva (joyce.eng07@gmail.com) and R. G. Alvares (rafalvares@gmail.com) are currently studying for a Bachelor's degree in Electronic and Telecommunication Engineering at Pontifical Catholic University of Minas Gerais (PUC Minas), Belo Horizonte, 30535901 Brazil).

W. A. Jesus is with Federal University of Minas Gerais (UFMG), Brazil.

E. J. G. Lima is with Serviço Nacional de Aprendizagem Industrial (SENAI), Brazil

Z. M. A. Peixoto is with Electronic and Telecommunication Department and Graduate Program in Electrical Engineering of Pontifical Catholic University of Minas Gerais (PUC Minas), Belo Horizonte, 30535-901 Brazil (assiszmp@pucminas.br).

\section{Vibrations in Civil Structures}

Vibrations are usual occurrences in civil structures, since these structures are constantly subject to mechanical efforts and have a limited level of rigidity. Despite being robust to these types of effects, several problems can emerge when the vibration intensity exceeds the maximum tolerance [2] [3].

In a system, the change rate in its dynamic forces generated from external influences is a quantity named vibration, that is, vibration is any repetitive motion that occurs in structures when these are subjected to external stimulation. The structure can vibrate at ever greater amplitudes causing the resonance effect, when the excitation frequency levels match the structure natural frequency, which will move with sufficient intensity to cause its collapse.

Mathematically, this motion can be represented by root mean square value (RMS) of acceleration, speed or displacement, which is an electrical quantity that effectively indicates the energy consumed in time-varying circuits and can measure the work performed, for instance the light generated, heat, etc. [4]. Thus, the RMS acceleration value in structures can provide the vibration energy measurement.

Considering the average power in a direct current (DC) circuit $P_{a v}(d c)$ equal to the average power of an equivalent alternating current $(\mathrm{AC})$ circuit $P_{a v}(a c)$, it leads to:

$$
\begin{aligned}
& P_{a v}(d c)=P_{a v}(a c) \\
& P_{a v}(d c)=\frac{v^{2}}{R} \\
& P_{a v}(a c)=\frac{1}{T} \int_{0}^{T} \frac{v(t)^{2}}{R} d t \\
& v(t)=A \sin (\omega t+\theta)
\end{aligned}
$$

where $v(t)$ is the applied voltage, $T$ is the signal period, $R$ is the equivalent load resistance, $\omega=2 \pi f$ is angular velocity, $A$ is the maximum voltage value and $\theta$ is the initial phase angle. Therefore, from equations (2) and (3), it is possible to calculate the applied voltage as (5):

$$
v(t)=\sqrt{\frac{1}{T} \int_{0}^{T} A \sin (\omega t+\theta)^{2} d t}
$$


Equations (1) to (5) will be used so that the measured voltage values can indicate whether vibration and displacement are within the specified value range.

\section{System Description AND OpERATION}

The system is powered by a lithium battery that can be charged by an electronic module connected to a micro USB cable or a photovoltaic panel. This power supply system allows the sensor to be used for a long time in remote areas far from urban centers, provided there is sunlight.

A module containing a gyro sensor and an accelerometer is used to measure vibration and position. In this project, only the accelerometer is used to indicate the system status, defined by calculating the vibration signal RMS values. The system has three Light-Emitting Diodes (LED) for status display, in a way that the green LED indicates acceptable levels of vibration and position, the yellow LED indicates alert and the red LED indicates critical situation. It is worth noting that the red alert may indicate an imminent sign of structural collapse, which can be life-threatening and cause property damage.

The vibration and position measuring device also includes a feature for displaying graphs generated from the gauged signals. An application was created on the Blynk platform for viewing, which is the interface between devices applied in Internet of Things (IoT) such as ESP 32, used for the project control. The sensor detects the signals and a microcontroller receives and forwards them to a smartphone. A key and significant point in the project is the possibility of viewing and controlling graphics anywhere in the world, if provided that Internet connection is available. What makes this possible is the use of the Blynk server, where the vibration and position values are stored and sent to a pre-defined cell phone.

Fig. 1 presents a prototype block diagram highlighting the power system, vibration and position signals, the proposed system main steps, the Blynk server and the cell phone for reception. These subsystems will be explained in more detail in Section V.

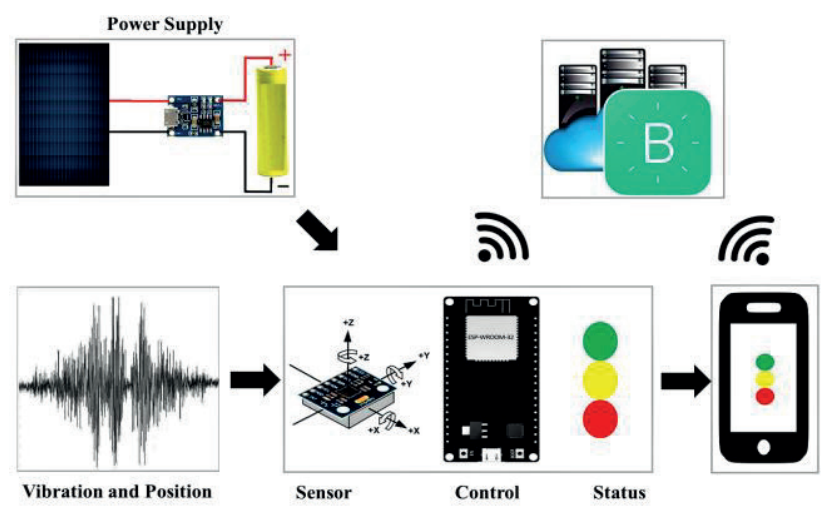

Fig. 1. Block diagram of the proposed system.

\section{PRototype DeVElopMent}

The prototype was developed by using a computer-aided designing (CAD) software [5] and built on a LPKF ProtoMat S63 prototype machine. which were integrated into a single Printed Circuit Board (PCB).

Fig. 2 shows the power supply module U1, a capacitor bank responsible for filtering the power ripple and high frequency noise, and a push-bottom that allows the user to choose the network to which the device will connect or if the connection should remain on the previously configured device.

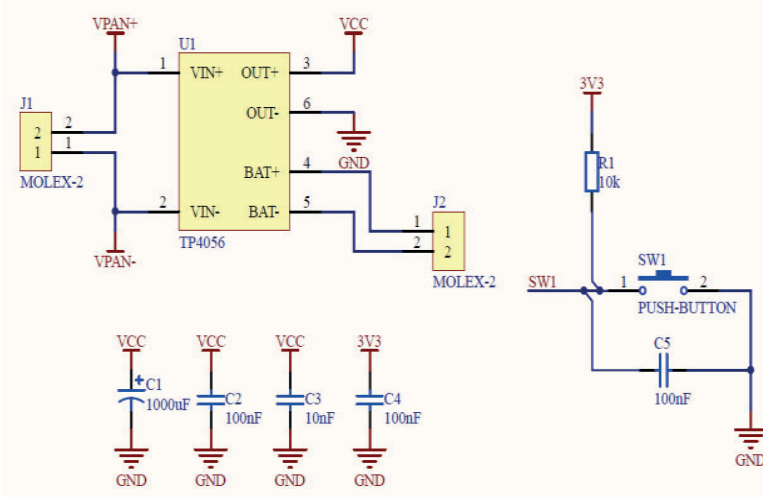

2. Charger module, capacitive filter and push button.

According to the electronic schematic shown in Fig. 3, module U2 is responsible for system control through the ESP32 microcontroller and MOD1 (GY-521) is responsible for receiving and processing vibration measurement signals. It also shows a set of 3 LEDs used for signaling monitoring status.

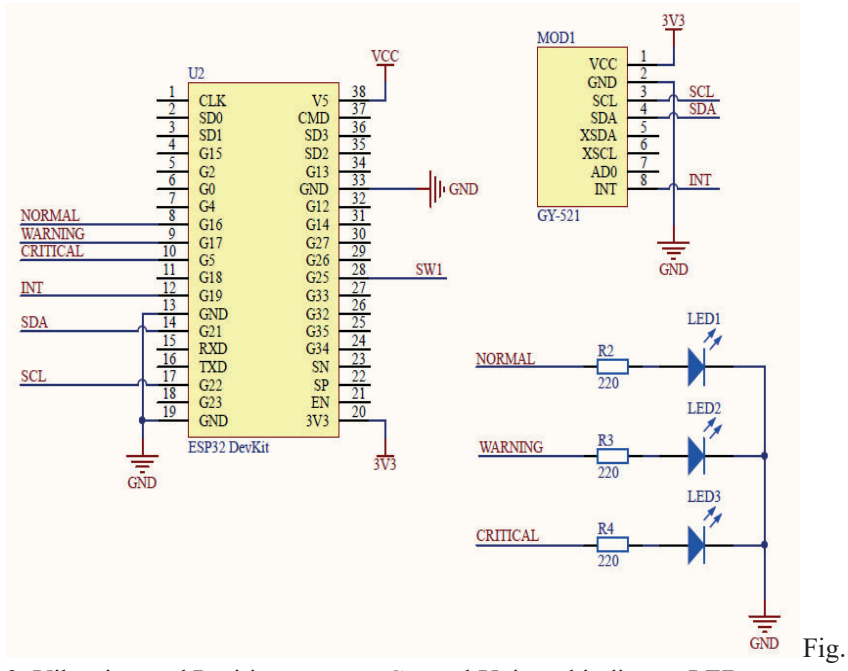

3. Vibration and Position sensors, Control Unit and indicator LEDs.

Fig. 4 and Fig. 5 show a 3D-version prototype and the version implemented after the board manufacturing, respectively.

Fig. 2 and Fig. 3 show the electronic modules schematics, 


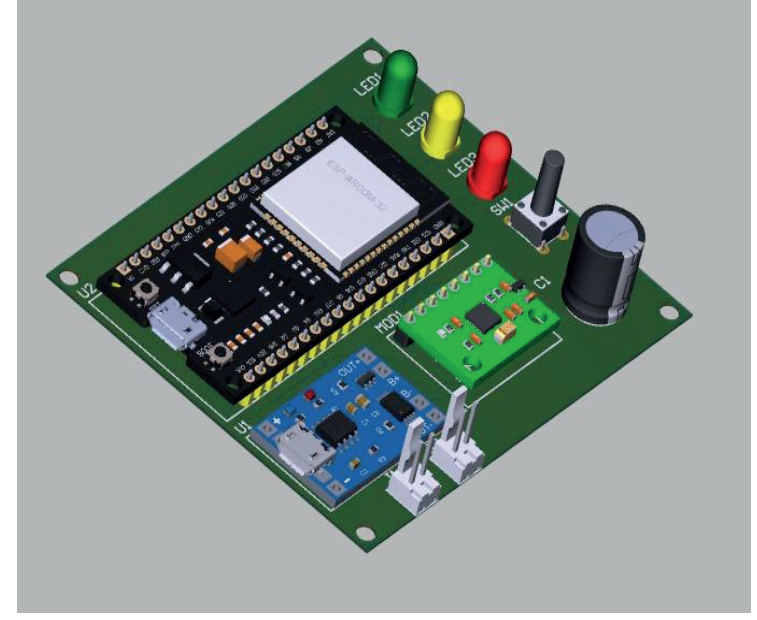

Fig. 4. PCB in $3 \mathrm{D}$ version.

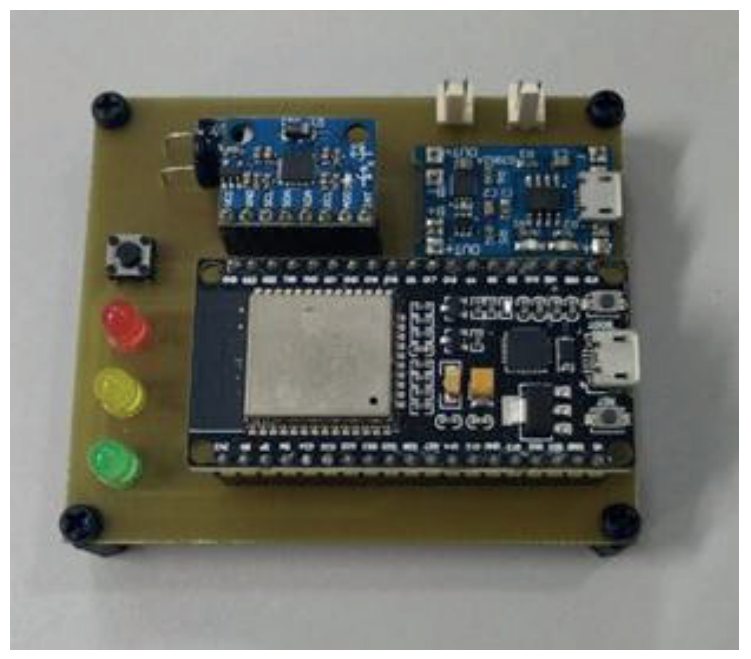

Fig. 5. The proposed system implemented in PCB

\section{Electronic DeVices}

\section{A. ESP32 Module}

ESP32-Wroom-32 [6] is a module that contains a high performance ESP32 microcontroller for low power, wireless communication applications. The board contains the ESP32 chip with built-in antenna, a serial USB interface and a $3.3 \mathrm{~V}$ voltage regulator. It is possible to program it in LUA or using Arduino Integrated Development Environment (IDE) by a micro USB cable. With a 4MB flash memory, ESP32 permits creating a variety of applications for IoT projects, remote access, webservers and dataloggers, among others.

Table I shows the specifications and Fig. 6 and Table II show the ESP32 module pin identification.

TABLE I

ESP32 TECHNICAL DESCRIPTION

\begin{tabular}{ll}
\hline \hline Items & Specifications \\
\hline CPU & Xtensa ${ }^{\circledR}$ Dual-Core 32-bit LX6 \\
ROM & 448 Kbytes \\
RAM & 520 Kbytes \\
Flash & 4 Mbytes \\
On-board clock & $240 \mathrm{MHz}$ \\
Bluetooth Protocol & BLE 4.2 \\
GPIO & 11 \\
GPIO Functions & PWM, I2C, SPI, etc. \\
Operating voltage & $4,5 \mathrm{~V} \sim 9 \mathrm{~V}$ \\
Transfer Rate & $110-460800 \mathrm{bps}$ \\
\end{tabular}

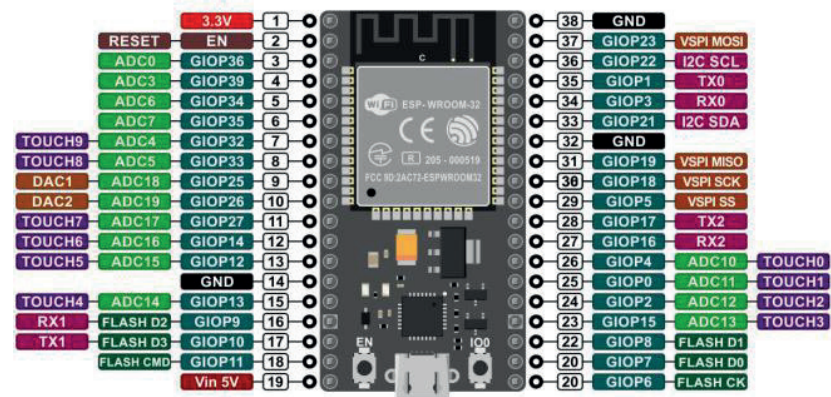

Fig. 6. ESP32 Pin Layout

TABLE II

ESP32 MODULE PIN IDENTIFICATION

\begin{tabular}{|c|c|c|}
\hline Pin Layout & Pin Description & Color Code \\
\hline $3.3 \mathrm{~V}$ & power supply & \\
\hline GND & ground & \\
\hline $\mathrm{ADC}$ & analog-to-digital converter & \\
\hline SP & serial interface & \\
\hline GPIO & general purpose input/output & \\
\hline DAC & digital-to-analog converter & \\
\hline TOUCH & capacitive touch sensor & \\
\hline Vin & Input power & \\
\hline
\end{tabular}

\section{B. MPU6050 Module (Accelerometer and Gyroscope)}

The MPU-6050 sensor module [7] contains an accelerometer and a Micro Electro Mechanical Systems (MEMS) gyroscope on a single chip. There are 3 axes for the accelerometer and 3 axes for the gyroscope, making it 6 Degrees of Freedom (6DOF).

This module is responsible for measuring vibrations in the system board, which represents slight variations in position. This project uses both functions, which enables the reading of vibrations in the $\mathrm{x}, \mathrm{y}$ and $\mathrm{z}$ axis.

The vibration sensor data is read through the SLC and DAS pins via an I2C communication aimed at connecting peripherals through two lines, serial data and serial clock, respectively. Fig. 7 and Table II show the MPU6050 module and its especifications, respectively.

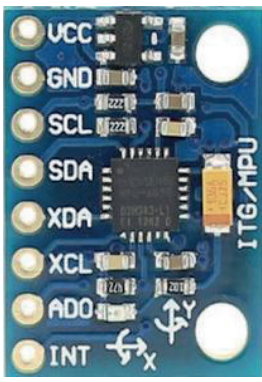

Fig. 7. MPU6050 Module

\section{TP4056 Battery Charger Module}

The TP4056 module [8] is a device used to charge batteries, especially lithium ones. It has a green LED to indicate that the charging process has been completed and a red LED to signal an ongoing charging process. It has a mini USB cable, which makes connecting easy, allowing batteries to be recharged without the need to remove them from the circuit. 
The TP4056 battery charger module is suitable for use in robots, drones and micro-controlled equipment, among others, and it makes recharging in the device itself possible. In the presented project, a mini photovoltaic panel was used to provide more autonomy and efficiency. Table III presents the TP4056 device specifications.

TABELA III

TP4056 SPECIFICATIONS

\begin{tabular}{ll}
\hline \hline \multicolumn{1}{c}{ Features } & \multicolumn{1}{c}{ Especifications } \\
\hline Operation Voltage & $5 \mathrm{~V}$ \\
Maximum current & $1 \mathrm{~A}$ (ajustable) \\
Output cut-off voltage & $4.2 \mathrm{~V}+/-1 \%$ \\
Overcurrent protection & - \\
Mini USB conection & - \\
Indicator LED & - \\
Operating temperature & $-10^{\circ} \mathrm{C}$ à $85^{\circ} \mathrm{C} 0$ \\
Size & $26 \times 17 \times 5 \mathrm{~mm}$ \\
\hline \hline
\end{tabular}

\section{Mini Solar Panel}

The mini solar panel is used for sustainable energy generation using sunlight, in which solar cells are responsible for capturing sunlight and electricity production. It is a device used in electronic project development to obtain electricity from renewable sources and it allows system operation in areas isolated from utility company power grids.

The mini solar panel makes it possible to connect to other panels in series or in parallel to generate higher voltages or currents. It will depend on the arrangement of how they will be assembled and electrically connected. In this project, the panel provides the electrical power required for the charger module, offering more autonomy and efficiency for the device. Table IV presents the mini solar panel specifications, whose structure is shown together with the battery charger module in Fig. 8.

TABELA IV

MINI SOLAR PANEL SPECIFICATIONS

\begin{tabular}{ll}
\multicolumn{2}{c}{ MINI SOLAR PANEL SPECIFICATIONS } \\
\hline \hline \multicolumn{1}{c}{ Recurso } & \multicolumn{1}{c}{ Especificação } \\
\hline Operation Voltage & $5 \mathrm{~V}$ \\
Power & $1 \mathrm{~W}$ \\
Maximum current & $200 \mathrm{~mA}$ \\
Size & $100 \times 69 \times 3 \mathrm{~mm}$ \\
Weight & $22 \mathrm{~g}$ \\
\hline \hline
\end{tabular}

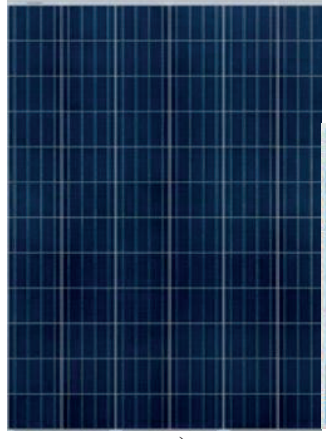

Fig. 8. a) Solar Panel b) Battery Charger

\section{E. Blynk Plataform}

The Blynk [9] is a platform for building IoT interface applications. It supports over 400 hardware modules, which includes Arduino, ESP32, Node MCU, raspberry and more. Internet connection is possible via WI-FI, bluetooth, ethernet, mobile, serial communication and USB. Blynk permits controlling hardware remotely, viewing and storing sensor data.

Basically, the Blynk plataform is made up of three parts consisting of Blynk App, Blynk Server and Blynk Library, as illustrated in Fig. 9.

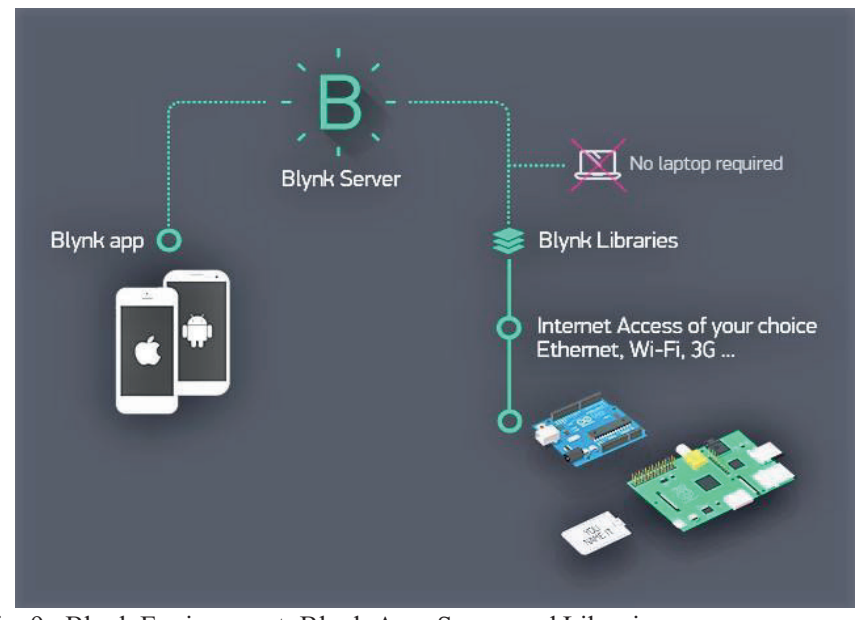

Fig. 9. Blynk Environment: Blynk App, Server and Libraries

Blynk App is available for Android and iOS operating systems and it allows the user to create applications that interact with the hardware. Through its own environment for each project, the user can insert widgets that implement control functions such as buttons, sliders, switches, and hardware data reading and notification, which are presented on displays, graphs and maps.

All communication between the application and user hardware is accomplished through the Blynk cloud. The server is responsible for transmitting data to the hardware, storing application and hardware status, and storing sensor data read by the hardware even when the application is not running.

It is noteworthy that the data stored on the Blynk server can be accessed externally through an HTTP API, which makes it possible to use Blynk to store periodically generated data such as temperature sensor data, among others.

Finally, on the hardware side there are the Blynk libraries for various development platforms. These libraries manage all hardware connection to the Blynk server, requests for input and output data and commands. Although it is easier and faster to use the library as Arduino, it is possible to obtain its versions for Linux, raspberry, python, LUA, among others. The Tests and Results section shows how the Blynk application was implemented.

\section{TESTS AND RESULtS}

Fig. 10 shows the interface developed for the proposed monitoring system. The three screens show the vibration and 
position signal variation graphs and provide the 3 vibration status indicators, which simulate the real LEDs signaling.

Another key point in this project is the possibility of presetting the values to desired levels of vibration and position, which makes the system implementable in any type of civil structure.
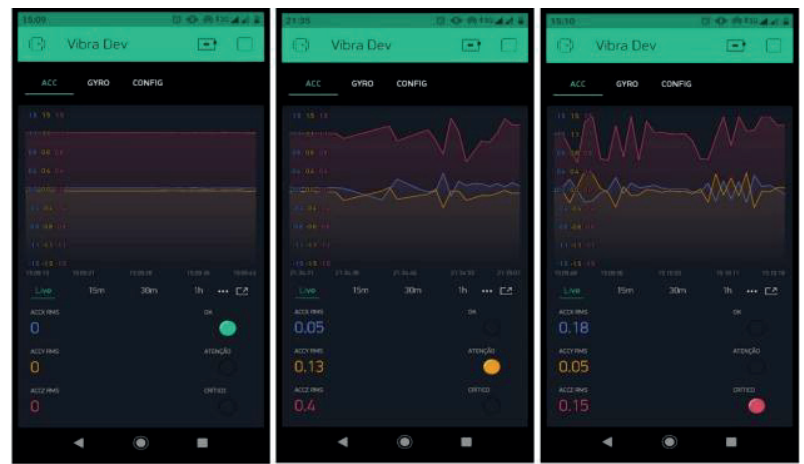

Fig. 10. Screen Interface of the MPU Module

\section{CONCLUSION}

This study presented the development and implementation of a prototype to analyze vibration and position signals. The proposed system based on the ESP32 and GY521 microcontroller was able to monitor civil structure status through acquisition and processing of measurement signals performed by a module composed by an accelerometer, a gyroscope and adjustable reference values.

The results were presented in a graphical interface with WI-FI communication using the Blynk platform for IoT interfaces.

Therefore, as it is a prototype, the system usage responded satisfactorily to the vibration levels adopted in the experiments within the scope of tests already performed

For future work, it is advisable to examine more effective and broader measurements that could generalize the application of such monitoring system to different civil structures.

\section{REFERENCES}

11] Chalouhi, "Vibration Based SHM of Railway Bridges Using Machine Learning: The Influence of Temperature on the Health Prediction", Springer International Publishing Ag, 2018. p. 200-211.

[2] F. Leonhardt, "Construções de concreto - Vol. VI - Princípios Básicos da Construção de Pontes de Concreto", Ed. Interiencia, $6^{a}$ ed, 2013.

[3] F. Hauksson, "Dynamic Behaviour of Footbridges Subjected to Pedestrian-Induced Vibration", Master's Dissertation, Lund University, Lund, Scania, Sweden, 2005. pp 29

[4] R. L. Boylestad, "Sinusoidal Alternating Waveforms," in Introductory Circuit Analysis, 12th ed. Pearson Education Limited, Ed. New Jersey: Upper Saddle River, 1913, pp. 572-578.

[5] Altium Designer software, www.altium.com/altium-designer/

[6] ESP 32. Site Espressif, 2019. Available:

https://www.espressif.com/en/products/hardware/esp32/overview

TDK InvenSense, 2019.2 Available: https://www.invensense.com/products/motion-tracking/6axis/mpu-6050/

[7] TP 4056. Site D\&amp;B Hoovers, 2019. Available:

https://dlnmh9ip6v2uc.cloudfront.net/datasheets/Prototyping/TP4056. pdf/

[9] Blyink, 2019. Available: https://blynk.io/

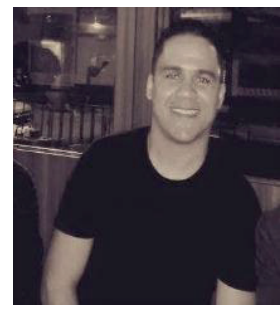

Wander P. de Jesus was born in Belo Horizonte city, Brazil, in 1980. He is electronic technician and undergraduate of Electronic and Telecommunication Engineering in Pontifical Catholic University of Minas Gerais (PUC Minas). Currently, he works at Federal University of Minas Gerais (UFMG) where searches on nanomaterials, as graphene and carbon nanotubes.

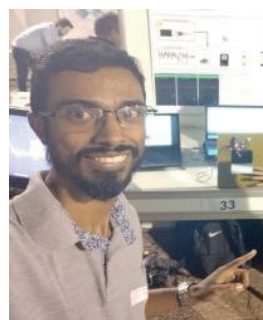

Evandro J. G. Lima was born in Belo Horizonte city, Brazil, in 1995. He is electronic technician and undergraduate of Electronic and Telecommunication Engineering in Pontifical Catholic University of Minas Gerais (PUC Minas). Currently, he is technology assistant in electronic innovation project development at SENAI -

CETEL, Belo Horizonte.

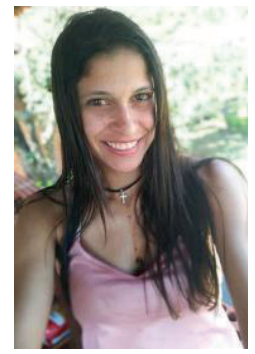

Joyce R. Silva was born in Belo Horizonte city, Brazil, in 1989. She is automation and control technician and undergraduate of Electronic and Telecommunication Engineering in Pontifical Catholic University of Minas Gerais (PUC Minas). At present, she is working as a trainee in electronic development at CBTU, Belo Horizonte.

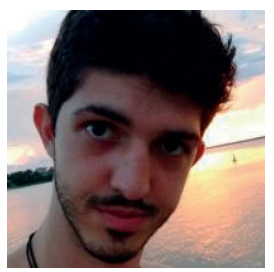

Rafael G. Alvares was born in Belo Horizonte city, Brazil, in 1996. He is electronic technician and undergraduate of Electronic and Telecommunication Engineering in Pontifical Catholic University of Minas Gerais (PUC Minas). At present, he is working as a trainee at MaisSI - FIEMG LAB4.0 Project.

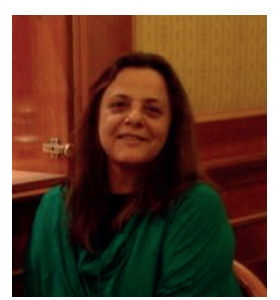

Zelia M. A. Peixoto received the Bachelor degree in Electronic and Telecommunication Engineering from the Pontifical Catholic University of Minas Gerais (PUC Minas) and Master and Ph.D. degrees in Electrical Engineering from the Federal University of Minas Gerais, in 1995 and 2001, respectively. She is an Associate Professor at the Graduate Program in Electrical Engineering and the Department of Electronics and Telecommunication Engineering at PUC Minas, Belo Horizonte, Brazil. 